\title{
The Removal of Nitrogen and Phosphorus from Sewage Effluents through the Use of Algal Culture* $\dagger$
}

\author{
V. Witt and J. A. BorchardT, Department of Civil Engineering, \\ University of Michigan, Ann Arbor, Michigan
}

Summary. This study is designed to establish fundamental data which will permit the eventual application of algal culture to the removal of nutrients from sewage plant effluents. A test cell is described which gives reproducible data when environmental parameters are varied. The effect of changes in temperature, light intensity and culture density as reflected in the growth rate, are shown, and the influence of these parameters on the removal of nitrogen and phosphorus under the test conditions indicated. The importance of an adequate carbon source and proper $\mathrm{pH}$ control is demonstrated. The organisms used were Scenedesmus and Chlorella in mixed or unialgal cultures.

Sewage plant effluents, even with an optimum combination of unit treatment processes, normally contain fragments of the original waste components. With population densities increasing rapidly and with the subsequent re-use of water, a stream may in time contain rather high concentrations of nutrients which in turn will stimulate intense algal growths where environmental conditions permit.

It would seem logical that if algal blooming is a result of nutrient discharge, this phase of biological assimilation could possibly be added as a tertiary stage of sewage treatment and kept within the confines of the sewage treatment plant. The objective of such a process would be to absorb the soluble nutrients by means of an actively metabolizing algal culture and then to

* Presented before the 136th National Meeting of the American Chemical Society, Atlantic City, N.J., September 1959.

† This research has been supported by a National Institute of Health Research Grant. 
remove the algae completely from the effluent before releasing it to the receiving waters.

Whether this objective can ever be realized depends first on the accumulation of sufficient knowledge concerning the life processes of useful algal species, and secondly upon man's ability to provide the required environment necessary to assure the successful growth of such species under artificial conditions.

The use of algal cultures to enhance the removal of organic constituents from sewage has had wide application in the form of lagoons or sewage ponds. An excellent review of the present information available in this area is afforded by the recent article of Fitzgerald and Rohlich. ${ }^{1}$

Present studies at the University of Michigan have been in progress since the fall of 1956, and are directed specifically towards the controlled use of algae in the sewage treatment cycle in contrast to the use of sewage lagoons which must be classed as an uncontrolled use.

As a first step towards the attainment of the objective of algal assimilation, batch cultures of local river water mixed with activated sludge effluent were incubated at $20^{\circ} \mathrm{C}$ under a light intensity of $200 \mathrm{ft} \mathrm{cd}$. Results from these studies indicated that Scenedesmus, Ankistrodesmus and Chlorella were the organisms most frequently produced. These algal species were isolated and used in subsequent experimental work. (Fig. 1.)

During the research programme, no attempt was made to maintain aseptic conditions since, in the event of the practical application of algal culture to sewage treatment, aseptic conditions would not be feasible. In the initial phases of the research a unialgal culture of Chlorella was the test organism; however, the culture tended to revert to a mixture of Scenedesmus and Chlorella with Scenedesmus predominating. This mixed culture has been under continuous test for a period of more than a year with little, if any, difficulty experienced in its maintenance.

The effects of light quality and intensity on algae have been widely considered by other investigators. ${ }^{2-5}$ Utilizing available data, a light source was constructed which would provide a major portion of its relative energy spectrum in the 400-700 $\mathrm{m} \mu$ range and with intensities varying from 100 to $2,000 \mathrm{ft} \mathrm{cd}$.

Shading effects were held constant by construction of a culturing 
device which poised the algal cell count at a definite level for a complete series of runs. This was accomplished by the use of light-sensitive cells placed on the back of the culture chamber (Fig. 2). Any change in transmittance of the culture due to growth actuated the photocells which, in turn, diluted the culture to the original concentration with fresh substrate. The volume of mixed liquor displaced was plotted automatically against time to provide a continuous visual curve showing the growth rate.
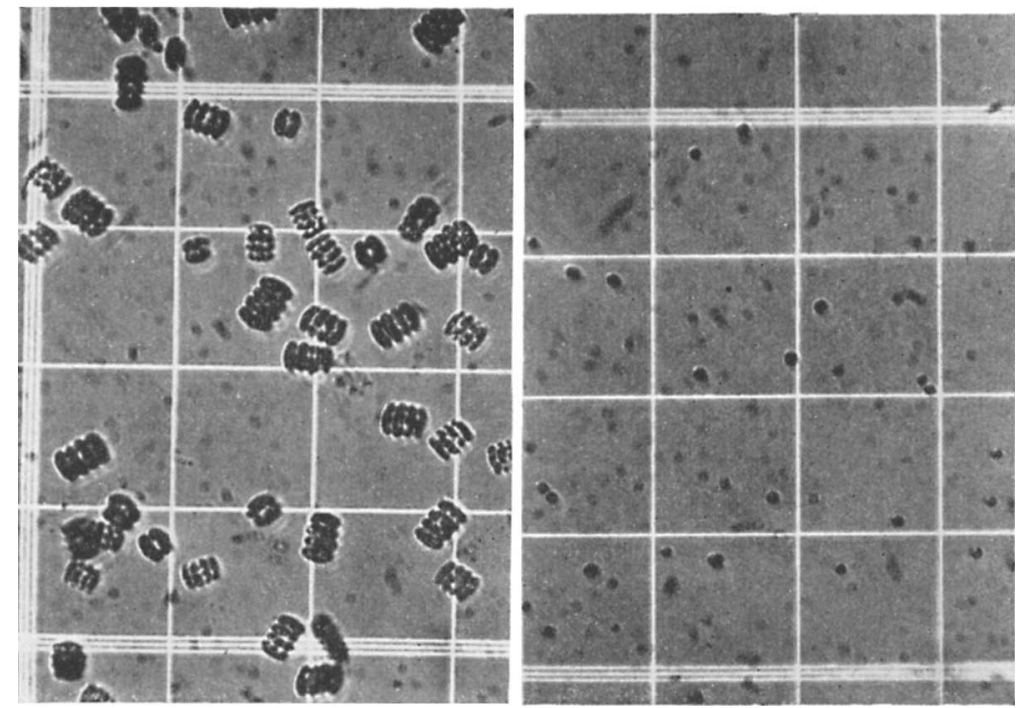

Fig. 1. (Left) Scenedesmus and (right) Chlorella; hemocytometer cell with markings at $50 \mu$ intervals

The initial volume of the culture was 3.41 , and the thickness $5 \mathrm{~cm}$.

In order to avoid inconsistencies due to slight changes in turbidity of the nutrient solution or changes in the light intensity due to line voltage variations, the differential photocell circuit of Wood, employing a control chamber, was used. ${ }^{6}$ The entire apparatus was enclosed in a room in which the temperature could be varied from 15 to $30^{\circ} \mathrm{C} \pm 0.5^{\circ}$.

The source of nutrients was secondary effluent from an activated sludge plant. A sufficiently large batch was obtained each 
time a run was contemplated, so that little change in the substrate occurred while data were being recorded.

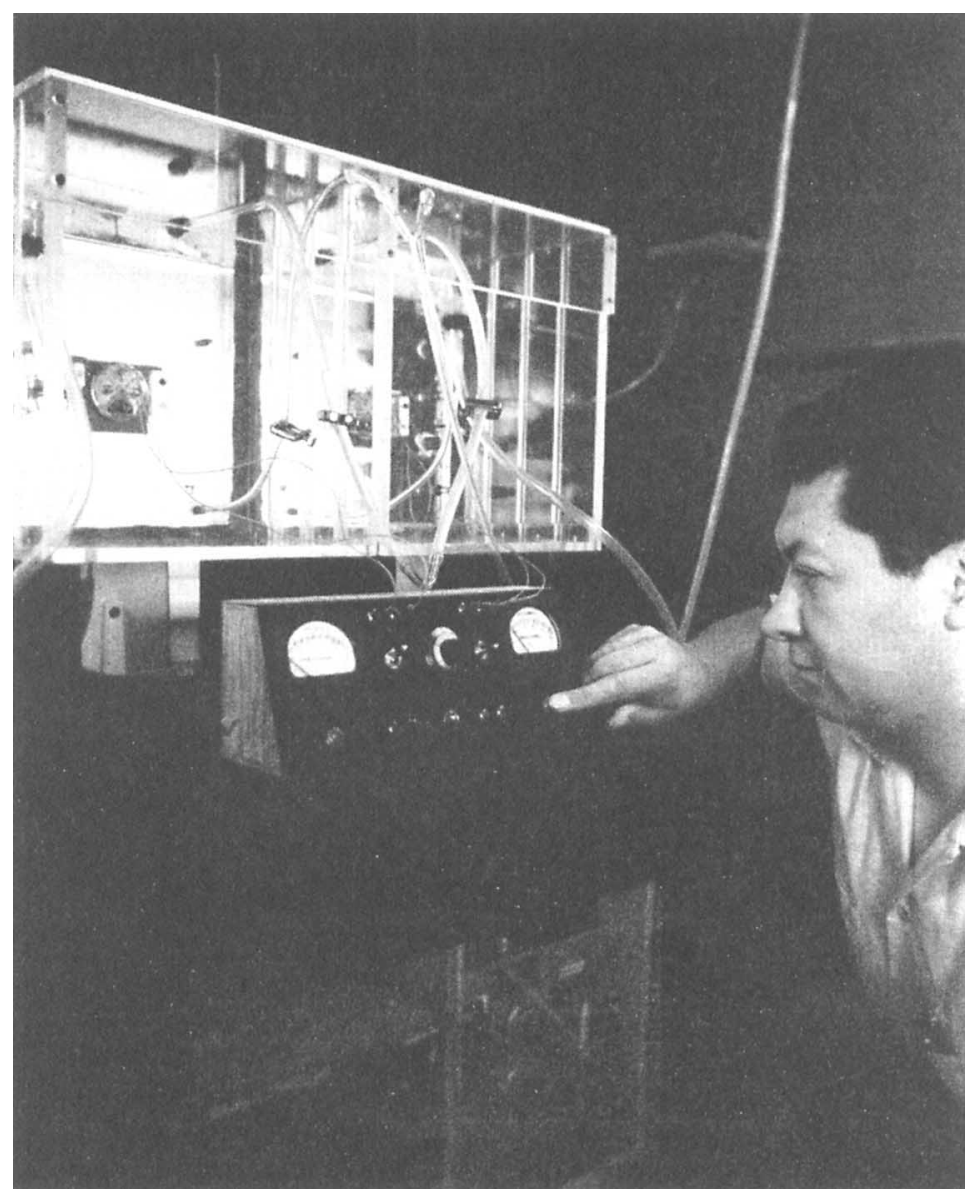

Fig. 2. Rear view of culture chamber showing photocells

As a supplement to the normal sewage nutrients, carbon dioxide was fed as a 5 per cent $\mathrm{CO}_{2}-95$ per cent compressed air mixture. In most runs a rate of 1 to $5 \mathrm{ml}$ per min proved entirely adequate for peak growth. Investigation to date has centred around two main objectives; first, the rate of growth of the test organisms 
utilizing sewage nutrients, and, secondly, the rate of removal of such nutrients.

Rate of growth has been measured by algal count and net cell volume, packed cell volume, dry weight and density, by optical density, and simply by displaced volume of mixed liquor.

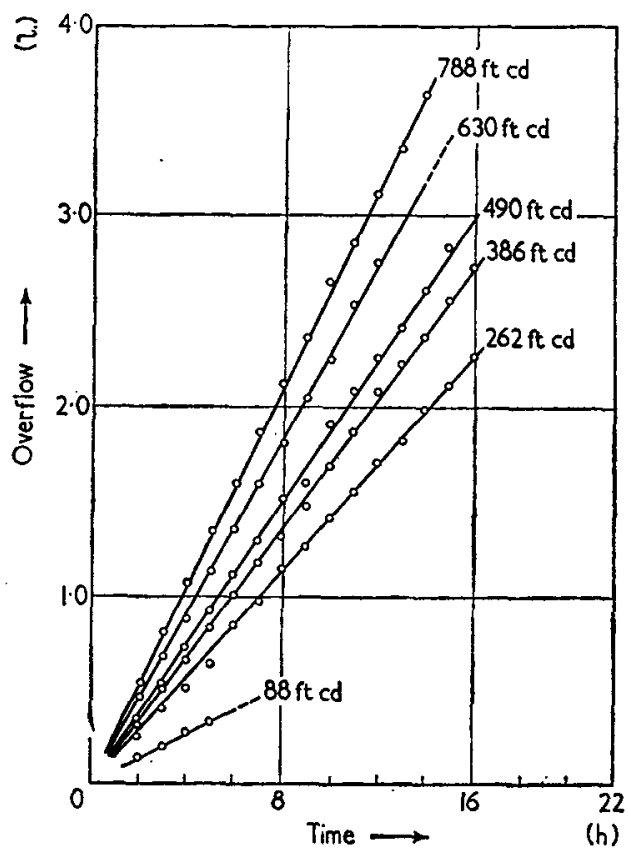

Fig. 3. Accumulated culture overflow as a function of time for various light intensities (Run $\mathrm{Ia}, 20^{\circ} \mathrm{C}$ )

Of the techniques enumerated, displaced volume seemed the most logical since it proved to be the simplest measurement to make and it was found that cell size, as well as cell density, apparently varied widely as environmental parameters were changed.

Fig. 3 shows the results of an early run with the equipment, and clearly illustrates the stability and sensitivity of the system as developed using the displaced volume as a measure of growth rate. This graph also demonstrates the suitability of secondary sewage effluent as a substrate. 
With all the important variables kept constant and with the growth established at a steady rate, it becomes possible to express the growth rate $k$ in terms of two parameters, namely, time and culture volume, through the following differential equation:

$$
\frac{d V}{d t}=k V
$$

From this expression integration yields the following solution for $k$ :

$$
k=\frac{1}{t} \log \frac{V_{2}}{V_{1}}
$$

Fig. 4 shows the relationship existing between growth rate as expressed by $k$ and light intensity at the surface of the culture.

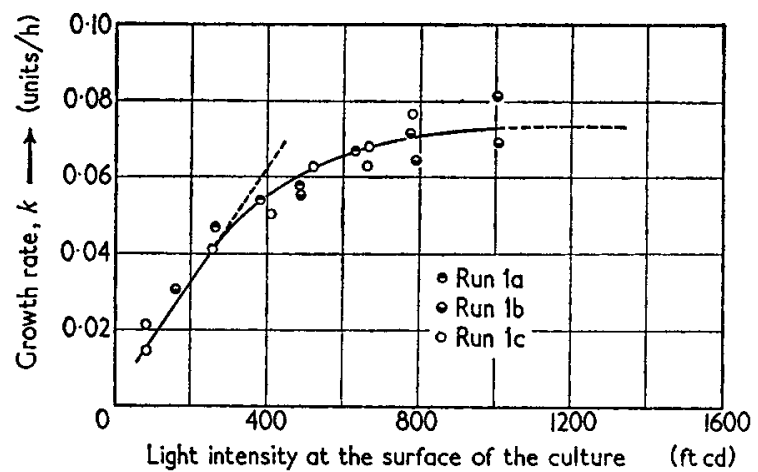

Fig. 4. Growth rate of Chlorella as a function of light intensity in secondary effluent $\left(20^{\circ} \mathrm{C}\right)$

Reference to Fig. 4 indicates that at low light intensities, with all other independent variables controlled, a direct proportionality between growth rate and light intensity is apparent. With a further increase in light intensity, the rate of change of growth rate is reduced and at high light intensities an adverse or toxic effect is produced. These results have been observed by other research workers studying the production of algae using synthetic media.

It is interesting to note that, in comparison to synthetic media, 
secondary sewage effluent appears to be a very acceptable substrate. This fact is indicated by a comparison of growth rate curves. Both shape of curve and peak rate of growth appear to be virtually the same when either medium is used.

Temperature effects are shown in Fig. 5 for the range between $20^{\circ}$ and $30^{\circ} \mathrm{C}$. Little, if any, effect on growth rate is apparent at low light intensities. At moderate to high light intensities, however, the light saturation intensity level (that intensity level at which the maximum rate of growth is attained) increases considerably with each five degree increase in temperature. There

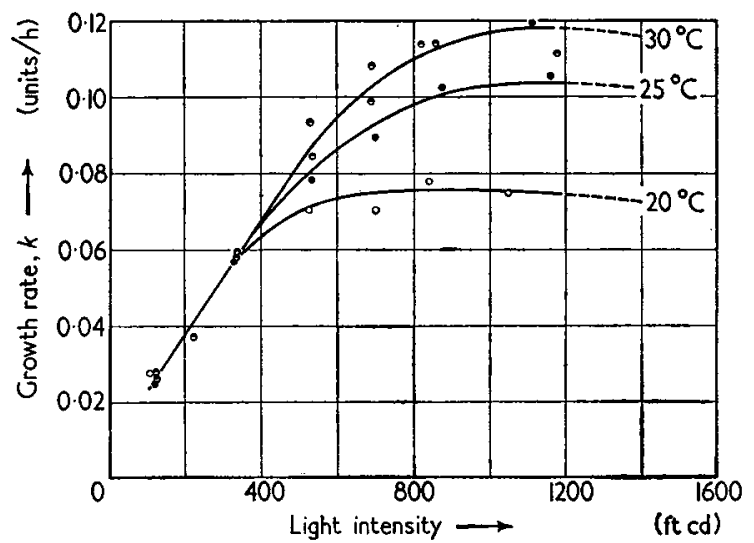

Fig. 5. Growth rate of a mixture of Chlorella and Scenedesmus as a function of light intensity at various temperatures

is evidently an intimate relationship between temperature and light intensity. This function is being given more adequate study.

Cell count or concentration of organisms is an important factor in the metabolism of algae. Fig. 6 indicates the change in growth rate experienced as the culture transmittance decreases. Above the level of 60 per cent transmittance the growth rate appears to be relatively independent of the number of organisms. Whereas, below this point growth rate is seriously impaired by an increase in cell concentration.

Such a drop in growth rate may be due to any one or a combination of several factors. It is possible that the cells are 
experiencing periods of reduced light exposure, or that inhibitive competition exists, or that toxic products are being formed. Further study of varying depths of culture at varying nutrient levels is necessary to define this relationship more clearly.

The carbon content of secondary sewage is also quite a serious problem in relation to cell concentration. Scenedesmus readily utilizes the bicarbonate form of alkalinity and thus tends to increase the $\mathrm{pH}$ of the culture. Good growth was observed at all

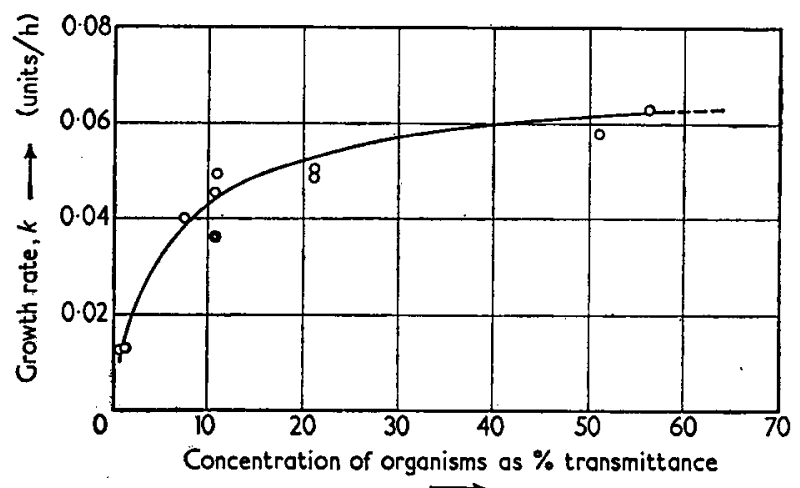

Fig. 6. Growth rate of a mixed culture of Chlorella and Scenedesmus as a func. tion of concentration of organisms $\left(20^{\circ} \mathrm{C}\right.$ and $\left.670 \mathrm{ft} \mathrm{cd}\right)$

$\mathrm{pH}$ levels from $6 \cdot 0$ to $9 \cdot 5$ with the best growth at $\mathrm{pH} 8 \cdot 3$. The secondary sewage used as substrate had a total alkalinity averaging $120.0 \mathrm{ppm}$ as $\mathrm{CaCO}_{3}$ (Table I) and an ammonia nitrogen

Table I. Composition of activated sludge effluents used in these experiments

\begin{tabular}{|c|c|c|c|c|c|c|}
\hline & Alk & $\mathbf{N H}_{3}$ & $\mathrm{NO}_{2}$ & $\mathrm{NO}_{3}$ & T.I.N. & $\mathrm{PO}_{4}$ \\
\hline Series I & $204 \cdot 6$ & $23 \cdot 3$ & $0 \cdot 47$ & 0.18 & $23 \cdot 98$ & $8 \cdot 7$ \\
\hline Series III & $181 \cdot 0$ & $20 \cdot 5$ & $1 \cdot 20$ & $\mathbf{1} \cdot 58$ & $23 \cdot 27$ & $9 \cdot 0$ \\
\hline Series IV & $120 \cdot 0$ & $15 \cdot 96$ & $1 \cdot 27$ & $7 \cdot 80$ & $24 \cdot 99$ & $20 \cdot 0$ \\
\hline
\end{tabular}

content of $16 \mathrm{ppm}$ as $\mathrm{N}$. This type of substrate was capable of supporting 1,000 Scenedesmus cells per $\mathrm{mm}^{3}$. Beyond this level carbon became limiting and an additional amount was supplied 
in the form of carbon dioxide. Fig. 7 shows a typical run at 1,500 Scenedesmus cells per $\mathrm{mm}^{3}$. The slope of the curve indicates the rate of growth which is steady at point $A$. When the $\mathrm{CO}_{2}$ source is shut off, the culture gradually adapts itself to the bicarbonate as a carbon source (point $\mathrm{C}$ ), and subsequently depletes this reserve before growth ceases at about $\mathrm{pH} 10.0$ (point $\mathrm{E}$ ).

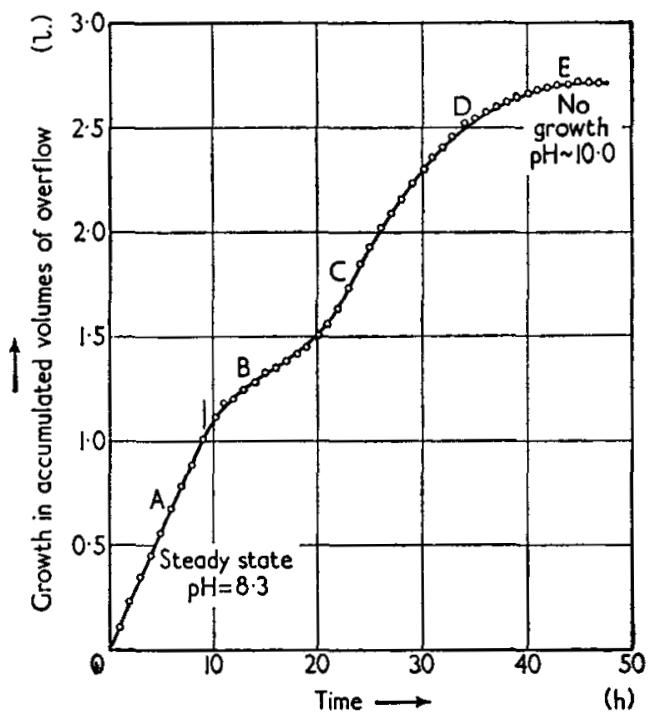

Fig. 7. Changes in the growth of a culture of Scenedesmus when available carbon is less than required $\left(20^{\circ} \mathrm{C}, 660 \mathrm{ft}\right.$ cd and $\left.1,500 \mathrm{org} . / \mathrm{mm}^{3}\right)$

Fig. 8 shows the growth pattern of a culture containing 12,000 Scenedesmus cells per $\mathrm{mm}^{3}$. This culture was aerated with 100 per cent carbon dioxide until growth ceased at $\mathrm{pH} \mathbf{5 \cdot 5}$. When the carbon dioxide feed was stopped the culture gradually resumed growth, utilized all the free and half-bound carbon, and finally the growth again ceased at a $\mathrm{pH}$ of $11 \cdot 0$. The lack of a lag phase in this case between the metabolism of free carbon dioxide and the bicarbonate may be attributed to the extreme competition in this rather dense culture.

Concentration of organisms also seems to play an important part in the efficiency of both production of cells and nutrient removal. Figs. 9 and 10 illustrate this point. Both the weight 
and volume of algae produced are a maximum at one level of energy absorption. The removal of inorganic nitrogen from the medium is also optimum at or near this same level. Since absorption of the incident light is a function of the concentration

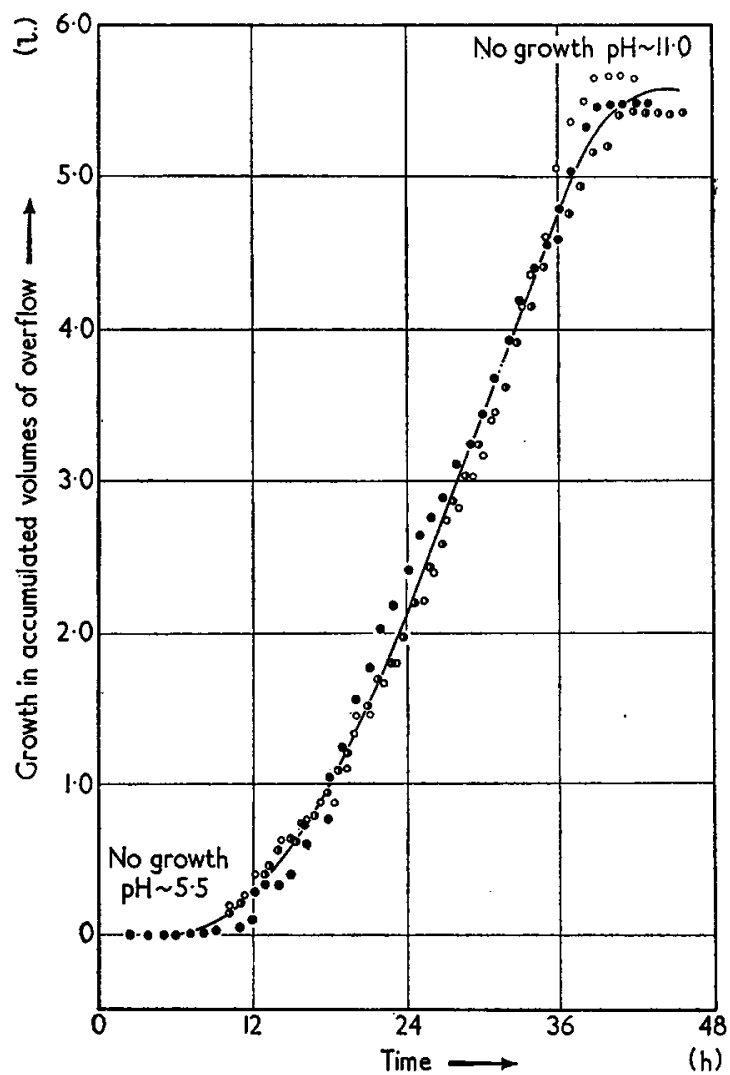

Fig. 8. Changes in the growth of a culture of Scenedesmus with depleting carbon available $\left(25^{\circ} \mathrm{C}, 1,050 \mathrm{ft}\right.$ ed and $\left.12,000 \mathrm{org} . / \mathrm{mm}^{3}\right)$

of the organisms, it may be concluded that there is one optimum level of cell concentration, other factors being constant, which will produce the most effective nutrient removal.

With the equipment and culture being used, the best removal came at 9,000,000 cells per $\mathrm{ml}$. This organism concentration corresponded to an optical density of 90 per cent. Reference to 


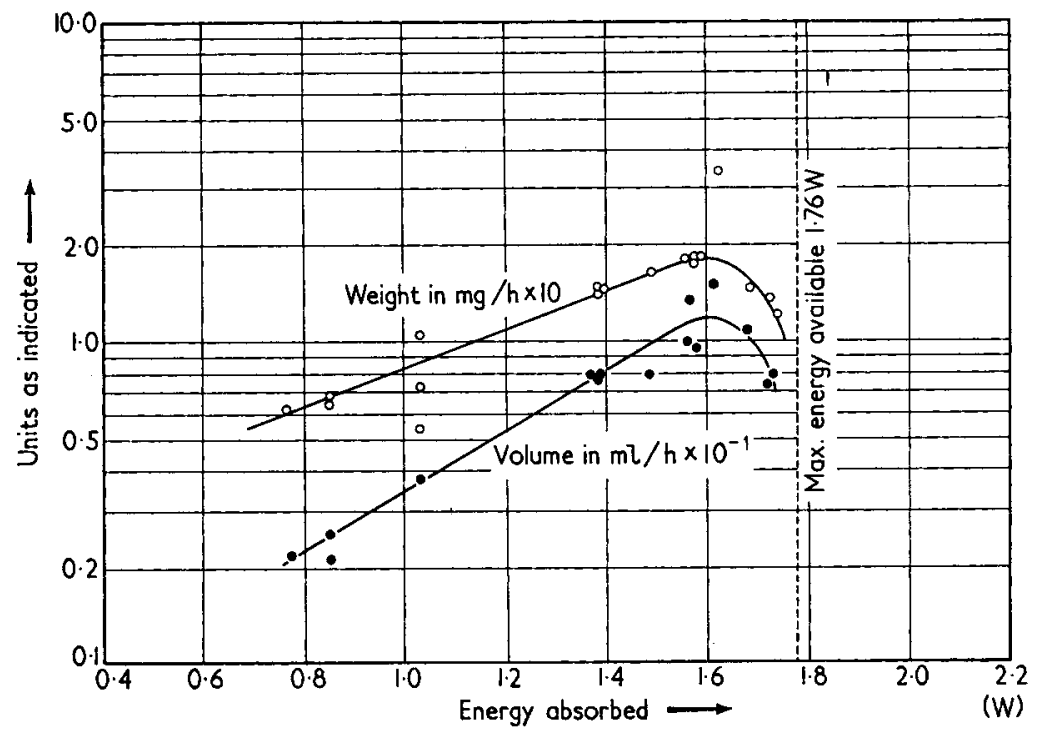

Fig. 9. Weight and volume of algae produced in a mixed culture of Chlorella and Scenedesmus as a function of the energy absorbed $\left(20^{\circ} \mathrm{C}, 670 \mathrm{ft} \mathrm{ed}\right)$

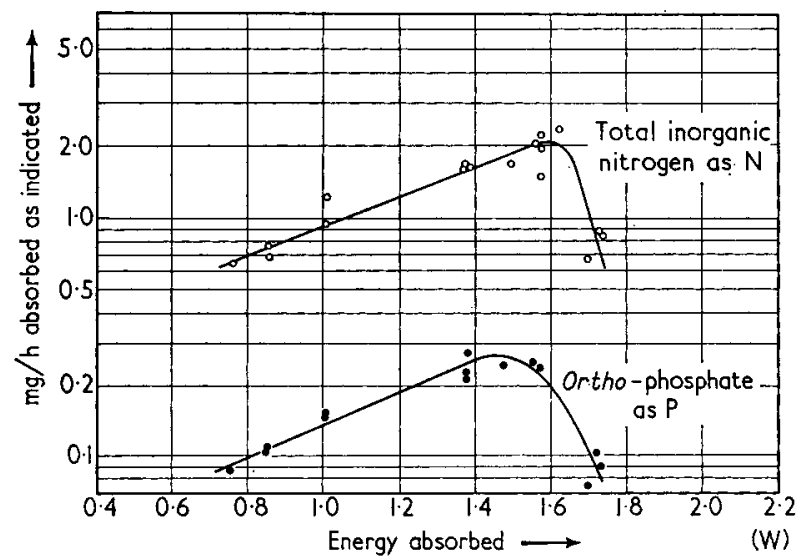

Fig. 10. Inorganic nitrogen and ortho-phosphate removed in $\mathrm{mg} / \mathrm{h}$ by a mixed culture of Chlorella and Scenedesmus as a function of the energy absorbed $\left(20^{\circ} \mathrm{C}\right.$, $670 \mathrm{ft} \mathrm{cd}$ ) 
Figs. 5 and 6 indicates that such a level of light transmittance would probably be well below the light saturation point. This fact implies that there is an optimum degree of shading or competition which actually results in the most effective culture as far as nutrient removal is concerned.

Fig. 11 indicates the effect of detention time on the removal of nutrients. Peak removal was attained in about $25 \mathrm{~h}$ with the type and concentration of organisms used. It should be noted that detention time here is based on the volume of overflow from

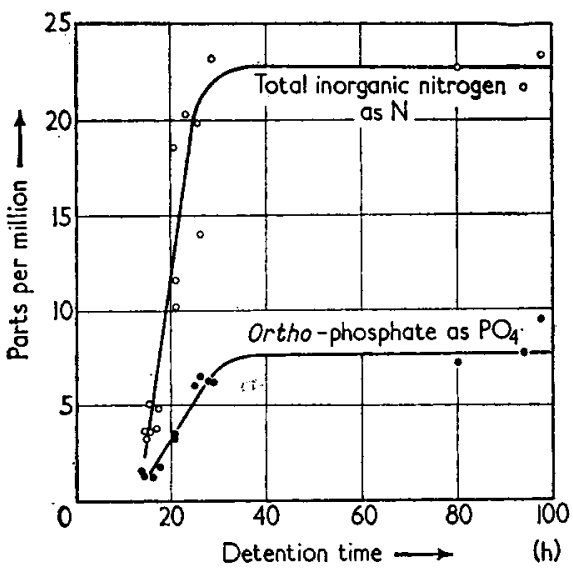

Fig. 11. Parts per million of nitrogen and phosphorus removed from the effluent by a mixed culture of Chlorella and Scenedesmus as a function of detention time $\left(20^{\circ} \mathrm{C}, 670 \mathrm{ft} \mathrm{cd}\right)$

a well-mixed, continuously fed culture cell. The effects of short circuiting in this case would be pronounced.

With regard to the effect of temperature on the process, Fig. 12 shows that at a temperature of $25^{\circ} \mathrm{C}$ a greater weight of organisms is produced than at $20^{\circ} \mathrm{C}$ for cultures having a comparable number of cells. This effect is made possible only by the expenditure of additional energy. At $20^{\circ} \mathrm{C}, \mathbf{1} \cdot 4 \mathrm{~W}$ of absorbed energy produced $15 \mathrm{mg}$ dry weight of algae per hour while, at $25^{\circ}$, the same expenditure of energy produced $9 \mathrm{mg}$ per hour. Within the limitations of the data taken up to this time the $20^{\circ} \mathrm{C}$ temperature level appears to be the most effective for nutrient removal.

The maximum dry weight production of organisms at $25^{\circ} \mathrm{C}$ 
was about $30 \mathrm{mg} / \mathrm{h}$. It is interesting to compare the maximum yield of cell material in these experiments with the values obtained by Ludwig et al. ${ }^{7}$ This author, under the same light and temperature conditions, cultured Euglena gracilis using settled raw sewage and supplemental carbon dioxide as a substrate. The reported yield was $0.26 \mathrm{gm} / 1$. day which compares within 4 per

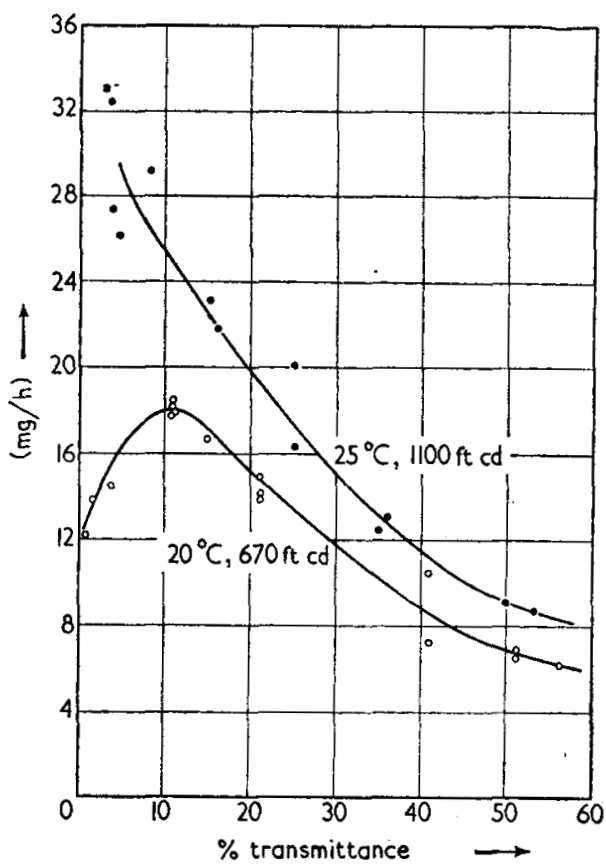

Fig. 12. Weight of organisms produced by a mixed culture of Chlorella and Scenedesmus as a function of transmittance

cent the yield reported here in secondary sewage. The implications of this fact would be that there are growth stimulating ingredients which may pass through a secondary treatment plant and which, to a large extent, negate the added degree of treatment as far as the production of certain algal forms in the receiving water is concerned. This assumes that a plentiful supply of carbon is readily available.

Fig. 13 shows the percentage of each form of inorganic nitrogen 


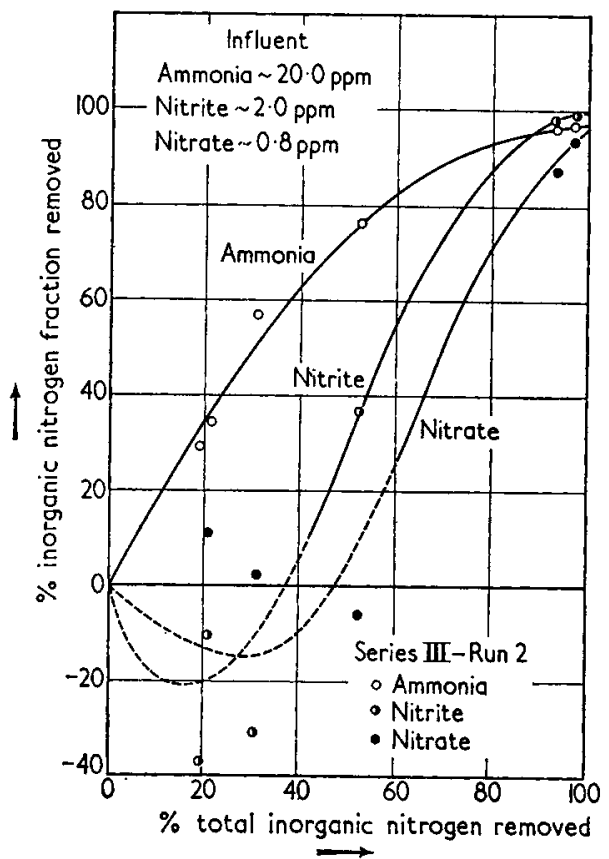

Fig. 13. Percentage inorganic nitrogen fraction removed as a function of the total inorganic nitrogen removed $\left(20^{\circ} \mathrm{C}\right)$

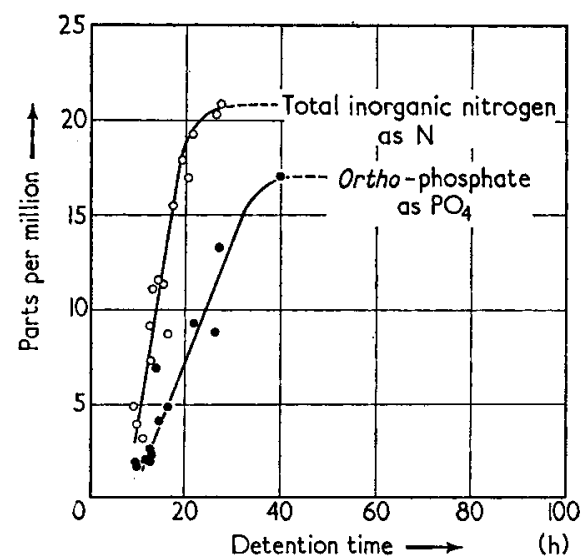

Fig. 14. Inorganic nitrogen and ortho-phosphate removed from the effluent by a mixed culture of Chlorella and Scenedesmus as a function of detention time $\left(25^{\circ} \mathrm{C}, 1,050 \mathrm{ft} \mathrm{cd}\right)$ 


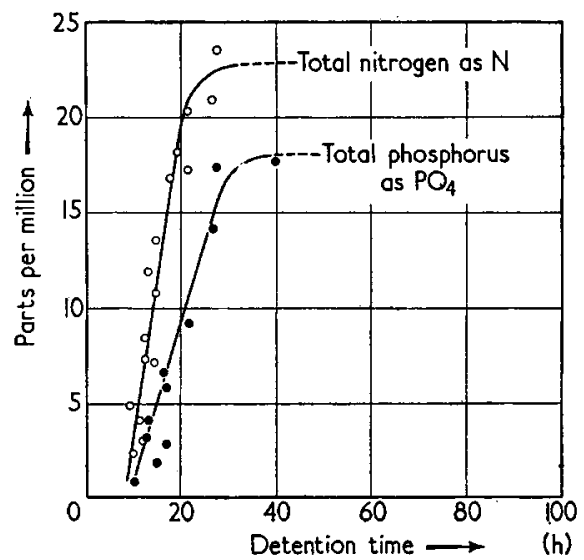

Fig. 15. Total nitrogen and phosphorus removed from the effluent by a mixed culture of Chlorella and Scenedesmus as a function of detention time $\left(25^{\circ} \mathrm{C}\right.$, $1,050 \mathrm{ft} \mathrm{cd}$ )

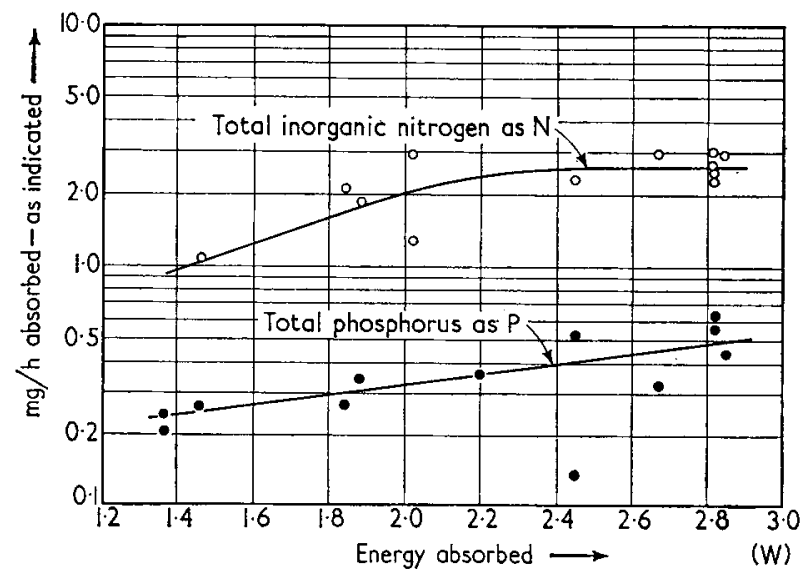

Fig. 16. Inorganic nitrogen and ortho-phosphate removed by a mixed culture of Chlorella and Scenedesmus as a function of energy absorbed $\left(25^{\circ} \mathrm{C}, 1,050 \mathrm{ft} \mathrm{ed}\right)$

removed. These data indicate that the ammonia nitrogen is the first form of nitrogen attacked. Figs. 14 and 15, when contrasted, indicate that the organic nitrogen fraction is probably attacked after the inorganic nitrogen and at the same rate. Fig. 11 indicates that the same rate of removal (in ppm) prevails 
at $20^{\circ} \mathrm{C}$ as at $25^{\circ} \mathrm{C}$ (Fig. 14). It should be noted that this is not true in the case of the removal of the phosphorus compounds.

Comparison of Figs. 10 and 16 would indicate that the efficiency of removal of inorganic nitrogen is somewhat higher at the lower temperature. Reference to Fig. 17, in contrast to Fig. 13, shows that the ammonia nitrogen is just about completely removed from

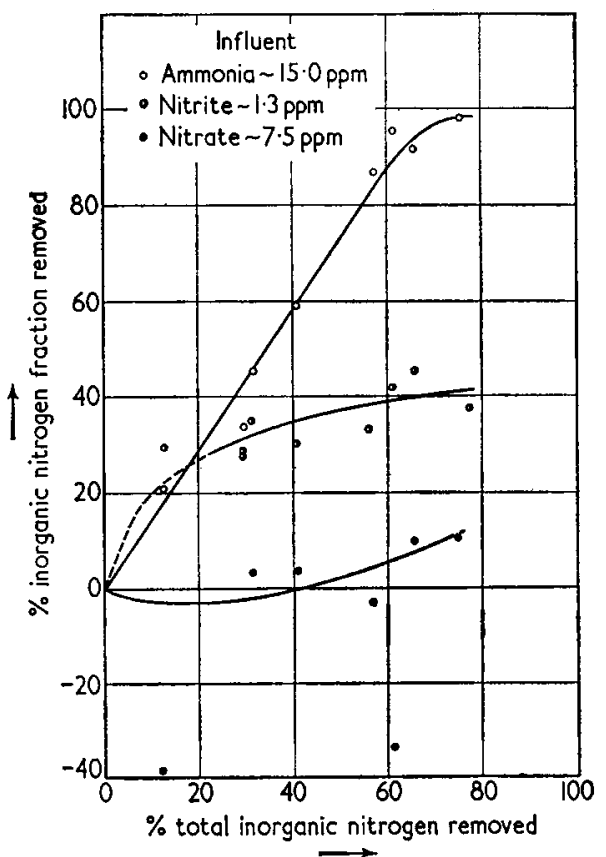

Fig. 17. Percentage inorganic nitrogen fraction removed as function of the total inorganic nitrogen removed $\left(25^{\circ} \mathrm{C}\right)$

the substrate. However, nitrites and nitrates are more slowly metabolized and, especially at the $25^{\circ} \mathrm{C}$ temperature level, are absorbed very ineffectively.

In contrast to nitrogen, both inorganic and organic phosphorus appear to be absorbed at the same time. In addition, phosphorus is removed more effectively at $25^{\circ} \mathrm{C}$ than at $20^{\circ} \mathrm{C}$. While phosphorus was never completely absorbed from the substrate, its removal continued long after the absorption of nitrogen had 
ceased. This fact would indicate storage of this element within the cell.

The observations reported on above indicate that good efficiency of removal of ammonia nitrogen can be expected within relatively short detention times. This compound appears to be found more frequently in high quantities in modern secondary sewage treatment effluents than is anticipated by many operators who fail to even test for it. Tertiary algal treatment is a possible technique for removal of this nutrient from the waste before discharge.

\section{References}

1 Fitzgerald G. P. and Rohlich, G. A. An Evaluation of Stabilization Pond Literature. Sewage industr. Wastes, 30, 1213 (1958)

2 Myers, Jack. Algal Cultures, Encyclopedia of Chemical Technology, First Supplement Volume. (1957). New York; Interscience Encyclopedia, Inc.

3 Harvey, H. W. The Chemistry and Fertility of Sea Waters. (1955). Cambridge University Press

4 Krauss, R. W. Photosynthesis in the Algae. Industr. Engng Chem. (Industr.), 48, No. 9 (1956)

5 Hollcender, A. Radiation Biology. Vol. III. (1956). New York; McGraw-Hill

6 Wood, A. A Differential Circuit for Blocking Photocells. Rev. sci. Instrum., 5, 295 (1934)

7 Ludwig, H. F. et al. Algae Symbiosis in Oxidation Ponds-I. Growth Characteristics of Euglena gracilis Cultured in Sewage. Sewage Industr. Wastes, 23, 1337 (1951) 